\title{
Improving the thermal performance of electrical transformers using hybrid mixture of (transformer oil, nanoparticles, and PCM)
}

\author{
Mushtaq I. Hasan ${ }^{a^{*},}$ Adnan A. Ugla ${ }^{a}$ and Hassan S. Kadhim ${ }^{a}$ \\ ${ }^{a}$ Department of Mechanical engineering, University of Thi-Qar, Thi-Qar, Iraq.
}

\section{ARTICLE INFO}

\section{Article history:}

Received 5 July 2020

Received in revised form 31 July 2020

Accepted 16 August 2020

\section{Keywords:}

Nanofluid

Electrical transformer

Transformer oil

Cooling performance

Distribution transformer

Transformer cooling

Phase change material

\begin{abstract}
A B S T R A C T
In this paper, an experimental electrical distribution transformer was studied and a new technique was proposed to improve the performance of a new mixed cooling consisting of pure transformer oil, paraffin wax and nanoparticles. The experiment was carried out on a small transformer that was done by taking a model with dimensions $(15 * 10 * 10) \mathrm{cm}$ to facilitate calculations. Paraffin wax absorbs the heat generated in the transformer due to the smelting process that can be used to cool electrical appliances. Nanoparticles have good thermal properties and lead to increased oil insulation to thermal improvements in transformer oil with dispersal of solid nanoparticles and their effects on transformer cooling. Three types of solid nanoparticles were used in this experiment $(\mathrm{Al} 2 \mathrm{O} 3, \mathrm{TiO} 2$, and $\mathrm{Sic})$ with a different volume concentration $(1 \%, 3 \%$, and $5 \%)$ and $4 \%$ paraffin wax as a certified added percentage for each process. The obtained results showed that when mixing paraffin wax and solid nanoparticles with transformer oil, the transformer cooling performance is improved by reducing the temperature. The best selected nanoparticles were found to be Sic and the reason for this is that Sic has a higher thermal conductivity compared to ( $\mathrm{Al} 2 \mathrm{O} 3$ and $\mathrm{TiO} 2)$. The proposed hybrid oil reduces the temperature by $10^{\circ} \mathrm{C}$ (in the case of PCM and Sic) and it is possible to improve the cooling performance of electrical transformers.
\end{abstract}

\section{Introduction}

The transformer is a constant electrical device that transmits electrical energy between two circuits. The transformer consists of three main components: the primary winding which functions as the input, the secondary winding which acts as the output, and the iron core which enhances the produced magnetic field. Nordman et al. [1]. A different current in one coil produces a heterogeneous magnetic flux, which in turn leads to a variety of wattages across the second coil around the same core. In 1831, Faraday discovered the induction law that described the effect of induced voltage in any winding, due to the change in magnetic flux surrounding the winding Bedell et al. [2]. Several experiments had been carried out to improve the efficiency of electrical transformers and to observe their behavior; Smith et al. [3]. COMSOL software was used to analyze numerically the dielectric changes and the resulting variable capacitance and dissipation parameters from moisture and temperature inputs. Their findings suggest a deeper understanding of modeling and study of OIP faults bushing. Amit M., et al [4]. Consider the insulation

* Corresponding author.

E-mail address: Mushtaq76@gmail.com (Mushtaq I. Hasan) 


\begin{tabular}{|c|c|c|c|}
\hline \multicolumn{4}{|c|}{ Nomenclature } \\
\hline A & area $\left(\mathrm{m}^{2}\right)$ & $\mathrm{H}$ & latent heat $(\mathrm{J} / \mathrm{kg})$ \\
\hline $\mathrm{Cp}$ & specific heat $(\mathrm{J} /(\mathrm{kg} \cdot \mathrm{K}))$ & $\mathrm{m}$ & mass $(\mathrm{kg})$ \\
\hline $\mathrm{Cpl}$ & specific heat of liquid $(\mathrm{J} /(\mathrm{kg} \cdot \mathrm{K}))$ & Q & heat stored $(\mathrm{J})$ \\
\hline Cps & specific heat of solid $(\mathrm{J} /(\mathrm{kg} \cdot \mathrm{K}))$ & $\mathrm{V}$ & volume (m3) \\
\hline $\mathrm{k}$ & thermal conductivity $(\mathrm{W} / \mathrm{m} \cdot \mathrm{K})$ & $\mathrm{K} 1$ & thermal conductivity at liquid state $(\mathrm{W} / \mathrm{m} \cdot \mathrm{K})$ \\
\hline $\mathrm{Ks}$ & thermal conductivity at solid state $(\mathrm{W} / \mathrm{m} \cdot \mathrm{K})$ & & \\
\hline $\mathrm{T}$ & temperature $(\mathrm{K})$ & $\mu$ & dynamic viscosity $(\mathrm{kg} / \mathrm{m} \cdot \mathrm{s})$ \\
\hline $\mathrm{TL}$ & temperature of liquidity $(\mathrm{K})$ & TES & thermal energy storage \\
\hline $\mathrm{Tpc}$ & phase change temperature $(\mathrm{K})$ & PCM & phase change material \\
\hline Ts & temperature of solidity $(\mathrm{K})$ & $\rho$ & density $(\mathrm{kg} / \mathrm{m} 3)$ \\
\hline
\end{tabular}

system for the power adapter bushing. Therefore, M4000 double capacity is used for the insulation analyzer. The bushings are represented as a critical element in the transmission of electricity. It is used in locomotives, transformers, and switches. Bushings cause more than $15 \%$ of transformer failures. The main purpose of the sleeve was to convey the current load in and out of the metal (ground) packages at the system voltage. The breakdown of the insulation system caused a bushing malfunction in the tank rupture, fire, and explosion of the bushing. The obtained results showed how the dielectric and humidity properties change with the different power factor and capacitance of the insulation system. Mushtaq I. [5]. A $250 \mathrm{kVA}$ transformer has been selected as a model to study the temperature range covering the hot weather. Nanofluids based on transformer oil has been used as a refrigerant medium. Four types of solid particles $\left(\mathrm{Cu}, \mathrm{Al}_{2} \mathrm{O}_{3}, \mathrm{TiO}_{2}\right.$, and $\left.\mathrm{Sic}\right)$ were used with nanofluid $(1 \%, 3 \%, 5 \%$, $7 \%$, and $9 \%$ ). Use the limited size method with a simple logarithm that was used to solve the problem of speed compression. The obtained results showed used nanofluids based on oil transformers a cooling medium leads to an increased in the cooling performance of the transformer by lowering the transformer temperature. The result of increased protection of the transformer parts. As a further step forward, in the same year, the same researcher Mushtaq I. [6]. Research published by the same work in the previous research. It used transformer oil that uses the existing MEPCM suspension as a cooling medium in place of pure transformer oil. Cooling oil for transformers consists of small capsules containing phase change substances called paraffin wax, surrounded a cap made of mixing polymers with pure transformer oil which results in a new mixture. Contributes more than pure oil to cooling portions of the transformer. This way it will increase the transformer's cooling capacity. This also increased the life span of the transformer parts. The $250 \mathrm{kV}$ transformer is designed with CFD, symbolized by the dimensions of real transformers. The small capsule contains paraffin wax as a PCM phase change material. Which dissolves inside the capsule after absorbing the heat from the cooling oil. The capsules used were mixed with cooling oil at volume rates ranging from (5 to 25) percentage. From the results, he concludes a decrease in mixture temperature and internal parts of the mixture transformer. Xiang Z. et al. [7]. Numerically studied a method for predicting flow distribution and pressure drop in forced oil- and cooling-directed mode disk-type transformer windings. Secondly, a dimensional analysis was conducted to determine independent variables in the winding that influence pressure drop and flow distribution. Next, CFD was used to conduct parametric sweeps simulations under isothermal flow conditions. Their results of flow distribution and pressure drop obtained from simulations were associated with variables that are not previously defined to derive correlation equations. These equations have been verified across a range of variables and applied to determine the inverse reversal criteria resulting. Mushtaq I. and Hind L [8]. Studied the effect in the micro-channel heat sink materials change phase. Air used in heat sinks for the first time and then used six PCM types (paraffin wax, n-eicosane, p116, and RT41). Have been used as cooling mediums in different configurations and different arrangement of heat sink at different ambient temperatures. The results exposed that the cooling performance of micro heat sink enhances due to using phase change materials in the heat sink. In addition, they concluded that selected the phase change materials should according to their melt temperature. In addition, according to a certain application due to the difference in melting temperatures of PCMs. The cost of materials used depends on the types of the PCMs (organic and inorganic), and the quantity of PCMs used in the application. As a further, step forward, in the same year, the same researchers Mushtaq I. and Hind L. [9]. Published research in the same procedures and action steps as in the previous research. However, using two types of PCMs (n-octadecane and RT44) and heat flux applied on the base of the heat sink is $640 \mathrm{~W} / \mathrm{m}^{2}$. The heat sink was used with unfanned and with three types of fins (square, triangular, and circular). Their results presented that, used the PCMs lead to improvement of the cooling enchantment of micro heat sink. In addition, values of heat reduction sink different according to different phase change materials used in a range of ambient temperature due to the difference in its melting temperatures. Mushtaq I. and Alaa A. [10] Presented a report on a transformer for electrical diffusion. It was tentatively concentrated, and a novel technique was suggested to improve its cooling efficiency by extending paraffin wax to transformer oil using aluminum shut-oil holders. Those compartments in the transformer oil were drenched. A 100-kVA transformer was used as a model for research on the grounds that typically such transformers are used in the power appropriation scheme in Iraq. The stage wax (paraffin wax) changes material as temperature rises assimilates warmth and melts inside the holders at a steady temperature. This element can be used to store heat for a period until the temperature for climate drops; at that point, this warmth is dismissed, and the wax starts to cement. Right now, holders were utilized, each containing $2 \mathrm{~kg}$ of wax. The outcomes indicated an away from in the temperature of the oil, which prompted the enhancement of its warm protection and kept the oil from disappointment and safeguarded the transformer from breakdown. The outcomes demonstrated that the decrease in temperature is around $7^{\circ} \mathrm{C}$ and the decrease expanded after expanding the measure of wax included. In this paper, a proposed new technique will be used to improve the thermal performance of electrical transformers using a hybrid mixture of pure transformer oil and paraffin wax and nanoparticles inside the transformer where paraffin wax absorbs the heat generated in the 
transformer due to the melting process. The nanoparticles have good thermal properties and lead to increased oil insulation Thus, this hybrid mixture absorbs the heat generated from the coils and pulp and keeps the transformer from collapsing.

\section{Materials and methods}

The experimental research and equipment used in the present analysis were based on a miniature model according to the standard (IEC60076) the electrical transformers. The experiment was done on a 100(KVA) mini transformer. This was done by taking a model with dimensions $\left(15^{*} 10 * 10\right)$ $\mathrm{cm}$ by scaling all dimensions of transformer oil in one scaling factor to facilitate the calculations. The studied transformer is compound of the following parts:

A- Oil tank: It is a tank made of hot rolled iron sheets formed according to the types of transformers and painted from the outside to prevent the arrival of moisture and not being affected by the external air conditions. Heat exchange between the transformer and the outer circumference as it is in the original transformer.

B- The electric heater: It is a small electric heater with a capacity of 60 watts and it is immersed in the oil tank. Cooling the transformers and it is used as a source of heat and its ability is controlled through the power regulator device it is used to simulate the heat generated from coils during real operation.

C- Power Regulator: It is a 4000 watt regulator that is connected between the electric heater and the electric power source, in addition to connecting each of the voltmeter and meter devices to control the current and voltage to obtain the required amount of heat.

D-Thermo-meter temperature recorder: It is an electronic device that is reliable in this experiment and contains twelve channels to record the temperature (Model: BTM-4208SD), its accuracy, $\left( \pm 0.4 \%+1{ }_{\circ} \mathrm{C}\right)$ and the range $\left(+999.9^{\circ} \mathrm{C}\right.$ to 50$)$ measuring the temperatures inside the transformer and outside.

E-Thermocouple: consist mainly of two part of semiconductors or dissimilar conductors. This part contraction each other at a connection and a voltage difference is formed when they inversely expand under the same temperature. The thermocouples used had a small wire diameter of 0.21 $\mathrm{mm}$ and a type $\mathrm{K}$ probe. Heat sensors were distributed inside the transformer a way to ensure that the average transformer oil temperature is obtained.

\section{Experimental procedure}

1- The transformer tank was filled with pure transformer oil of 1.5 liters and the electric heater was dipped inside the tank that is filled with transformer cooling oil and a data logger was attached to 12 temperature sensors as the first sensor is used to measure the ambient temperature, while the remaining eleven sensors They were distributed in order across the transformer, where 5 sensors were immersed at a height of $2 \mathrm{~cm}$ from the bottom surface of the transformer. As for the rest of the sensors, they were distributed at a height of $4 \mathrm{~cm}$ from the bottom surface of the transformer and different locations. The heater was equipped with an electric power of 60 watts through the power regulator.

2- This experiment was conducted in February as the transformer was placed in a closed room with heat sources on it the purpose is to raise the room temperature above $50^{\circ} \mathrm{C}$. The reason for this is that the experiment was carried out in the winter season and we cannot get a temperature of 50 ${ }^{\circ} \mathrm{C}$ or less.
3 - The readings were taken for about four hours in the case of high temperatures and the case of decline. Paraffin wax and nanoparticles were added with the same amount of energy as the electric heat and for the same time where 4 percent of paraffin wax was mixed and the ratio approved in this experiment with each of the metal nanoparticles, which includes both $\mathrm{Al}_{2} \mathrm{O}_{3}, \mathrm{TiO}_{2}, \mathrm{SiC}(1 \%, 3 \%, 5 \%)$ where it has been observed that when the wax is added by 4 percent to the three percentages for each substance, there is a decrease in temperature, especially when the percentage of $\mathrm{SiC}$ is increased and this is due to the high conductivity that Sic possesses compared to $\left(\mathrm{Al}_{2} \mathrm{O}_{3}, \mathrm{TiO}_{2}\right)$ where the process of adding each of the solid nanoparticles $\left(\mathrm{TiO}_{2}, \mathrm{Al}_{2} \mathrm{O}_{3}, \mathrm{SiC}\right)$ in ratios $(1 \%, 3 \%$ and $5 \%)$ for each substance to the pure transformer oil at a weight of $1.5 \mathrm{~kg}$.

4 - The $\mathrm{SiC}$ substance was taken at $1 \%$ of the weight of the pure oil and mixed it with pure oil and the same process for the remaining ratios of $\mathrm{TiO} 2$ as well as the same process for the two materials ( $\mathrm{Al} 2 \mathrm{O} 3$, TiO2). This process was performed in a basin containing an electric fan. As shown in Fig. 1.

5- The process of dissolving the wax was done by heating it in a container as shown in Fig. 2. As well as for the mixture consisting of pure oil and nanoparticle solid particles, from which the added wax proportions will be added to it as shown in Fig. 3. Table 1 shows the thermal properties of transformer oil and nanomaterials used in the experiment as well as paraffin wax.

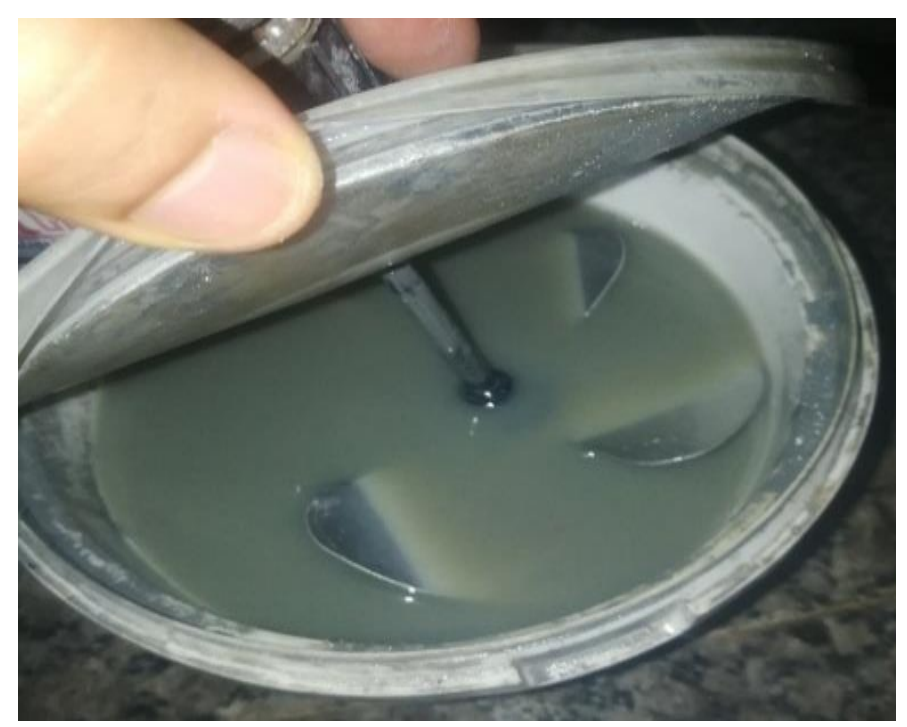

Figure 1. Shows the process of mixing Sic with pure oil. 


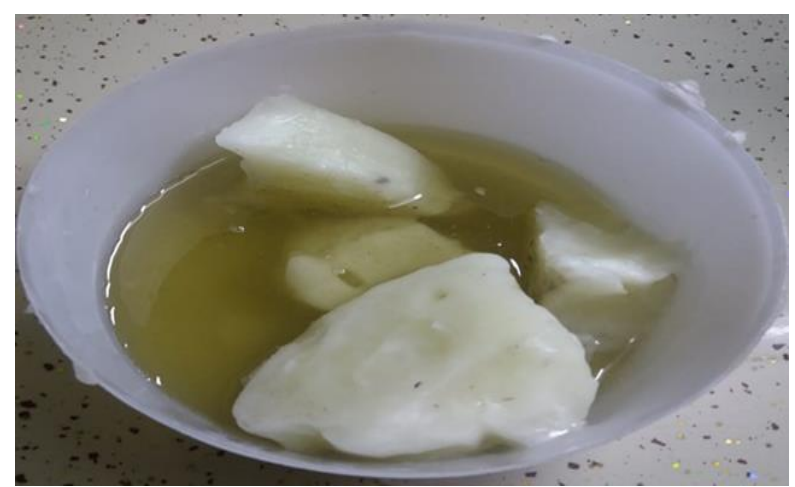

Figure 2. Melting wax and preparing it for mixing.
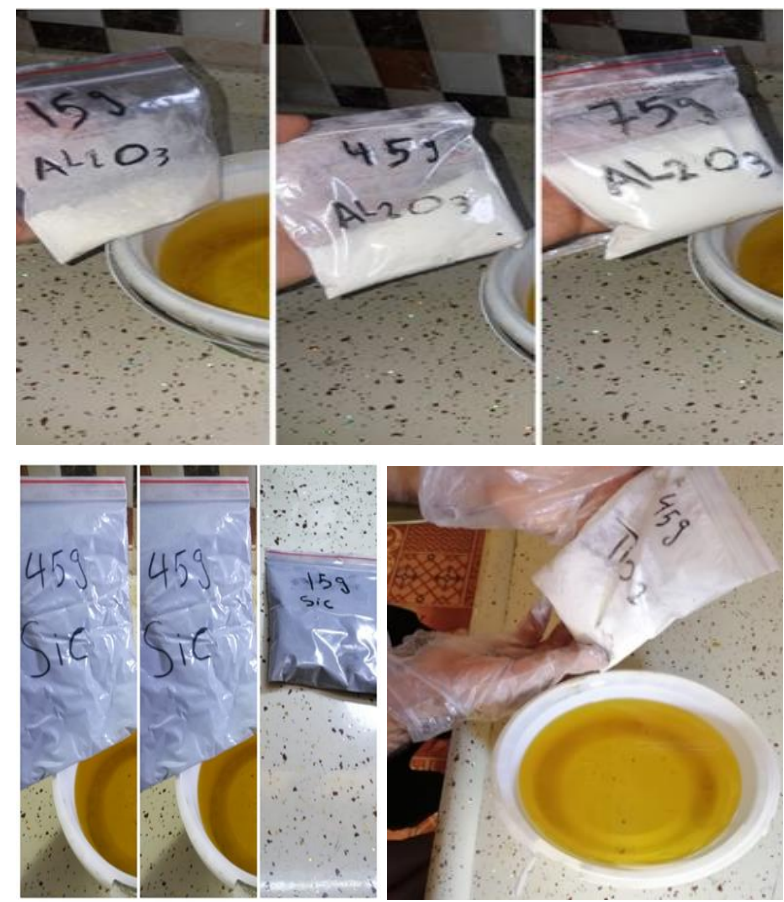

Figure 3. The stages of filling the tank with a mixture of transformer oil, paraffin wax and mineral particles

Table 1. thermo physical properties of the materials that used $[12][13][14]$

\begin{tabular}{|c|c|c|c|c|c|}
\hline $\begin{array}{l}\text { Type of } \\
\text { material }\end{array}$ & $\begin{array}{l}\text { Density } \\
\rho \\
(\mathrm{g} / \mathrm{m} 3)\end{array}$ & $\begin{array}{l}\text { Coefficient of } \\
\text { ythermal } \\
\text { conductivity } \\
\text { K } \\
\left(\mathbf{W} / \mathbf{m} .{ }^{\circ} \mathbf{C}\right)\end{array}$ & $\begin{array}{l}\text { Viscosity } \\
\text { Dynamic } \mu(\mathrm{kg} / \\
\mathrm{ms})\end{array}$ & $\begin{array}{l}\text { Specific } \\
\text { heat } \\
\text { Cp } \\
\text { (KJ / kg. } \\
\text { K) }\end{array}$ & $\begin{array}{l}\text { Anthulaby } \\
\text { of } \\
\text { Fusion } \\
\text { KJ / Kg }\end{array}$ \\
\hline $\begin{array}{l}\text { 1Transformer } \\
\text { Oil }\end{array}$ & 880 & 0.109 & 2 & 0.0124 & 0 \\
\hline $2_{\text {Wax }}^{\text {Paraffin }}$ & 773 & $\begin{array}{l}\text { Solid state }=215 \\
\text { And the liquid } \\
\text { state }=12\end{array}$ & $\begin{array}{l}\text { Solid state CPS } \\
=3.2 \text { and liquid } \\
\text { state } \mathrm{Cpl}=8.1\end{array}$ & 0.0063 & 179.6 \\
\hline $3 \mathrm{TiO}_{2}$ & 4250 & 8.953 & - & 686.2 & - \\
\hline $4 \mathrm{Al}_{2} \mathrm{O}_{3}$ & 3600 & 36 & - & 765 & - \\
\hline $5 \mathrm{SiC}$ & 3160 & 490 & - & 775 & - \\
\hline
\end{tabular}

The electric heater is a small electric heater with a capacity of 60 watts and it is immersed in the oil tank. Cooling the transformers is used as a heat source and controlled by the power regulator device Fig. 4 and the electric heater was used to replace the electrical coils as shown in Fig. $\mathbf{5}$.

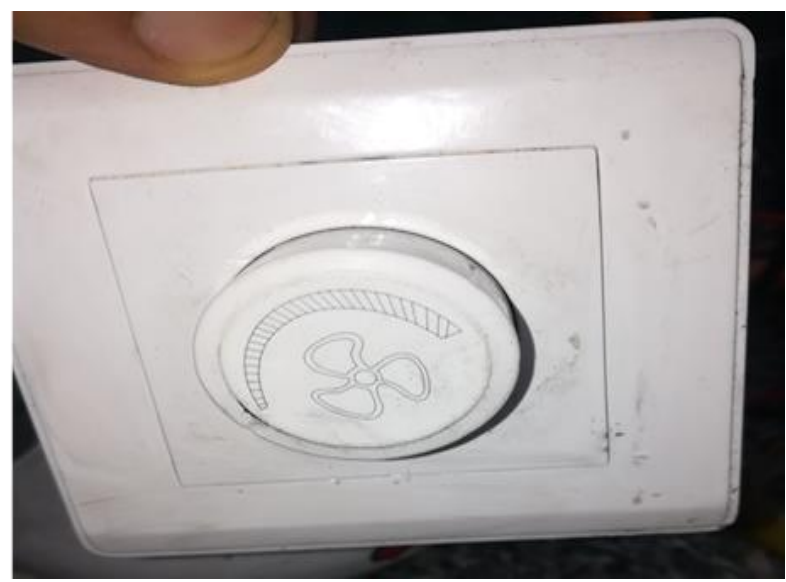

Figure 4. Power regulator

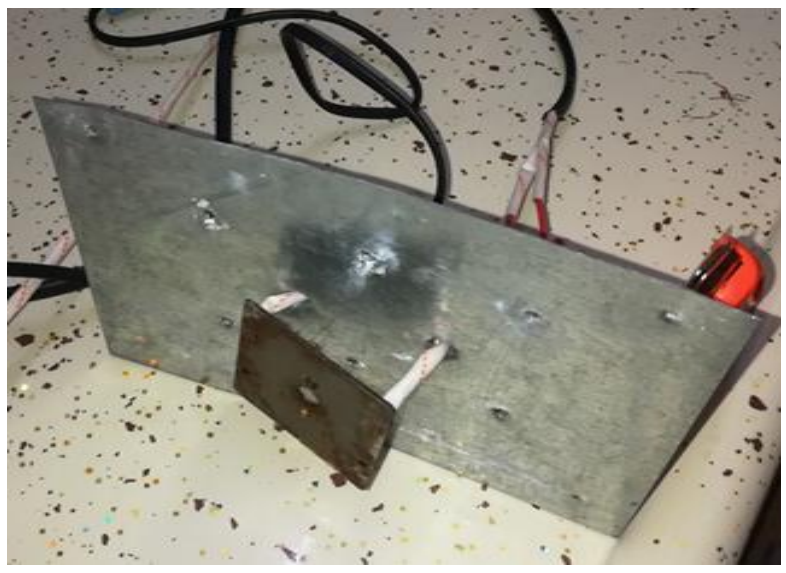

Figure 5. Electric heater

The temperatures were measured by thermal pairs and as shown in Fig. 6 and recorded using a data logger which contains 12 sensors as shown in Fig. 7 and Fig. 8 which shows the assembly and connection of the parts used in the experiment.

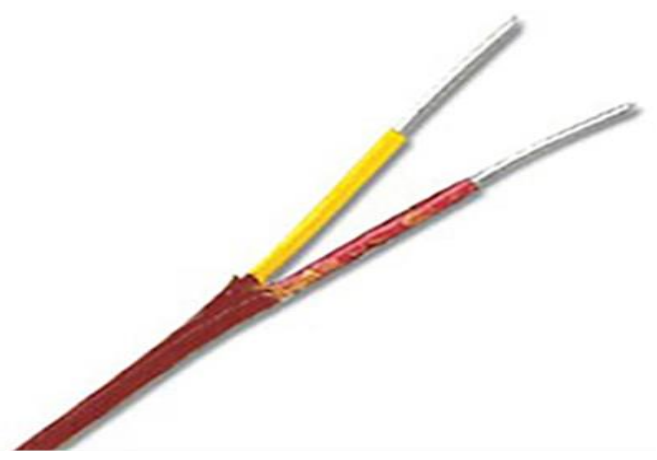

Figure 6. Thermocouples type $k$ 


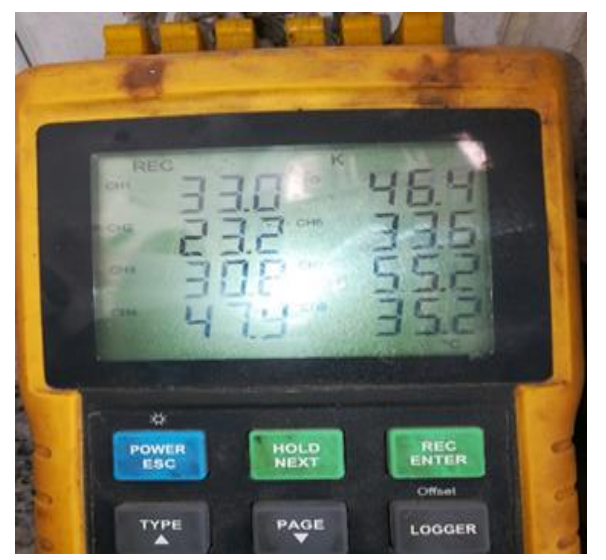

Figure 7. Temperature measuring device used in the experiment

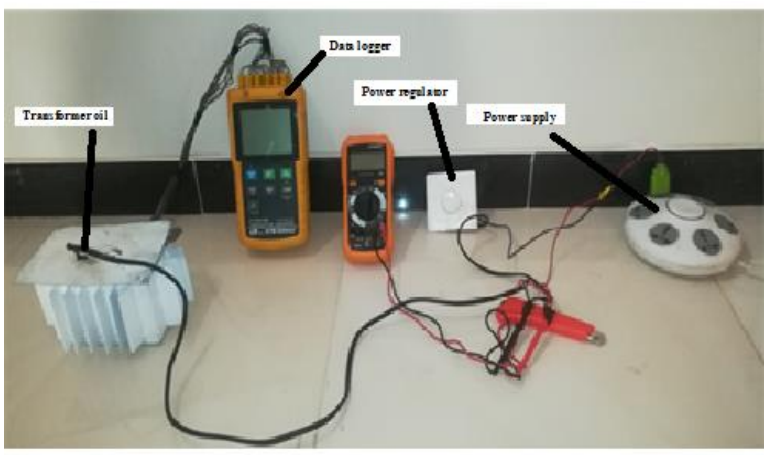

Figure 8. The assembly and connection of the parts used in the experiment

\section{Results and discussion}

Fig. 9 show the variable in mean temperature of the transformer with time of the coolants (pure transformed oil, transformed oil - PCM suspension, $\mathrm{TiO} 2$ nanofluid - oil suspension and hybrid suspension). It can be seen from the figure that the amount of latent heat absorbed by the PCMs for each PCMs to use increases with the increase in the ambient temperature due to the increase in the smelting portion as well as the increased heat absorbed with the increase in the amount of PCMs to use. This is normal, because the increase in the amount of PCMs means an increase in the average heat storage to an increase in the volume of latent heat taken up by the oil. In addition, $\mathrm{TiO} 2$ nanofluid has been used in different concentrations, which in turn reduces the transformer temperature due to thermal conductivity, which leads to improved heat transfered process by enhancing the thermal conductivity of the oil by dispersing nanoparticles and the thermal conductivity with a rise in the $\mathrm{TiO} 2$ nanofluid volume portion. Fig. 10 shows the variation in mean temperature of the transformer with time to the pure transformer oil, the transformed oils - PCM suspension and $\mathrm{A} 12 \mathrm{O} 3$ nanofluid - oil suspension and hybrid suspension. From this figure it can be observed that when using wax with Al2O3 nanofluid leads to a decrease in temperature which is due to this because paraffin wax has a high ability to store heat by absorbing it in the form of latent heat. It also increases the decrease in the temperature of the transformer when adding $\mathrm{Al} 2 \mathrm{O} 3$ nanofluid, because of the high thermal conductivity of us leads to an increase in the rate of heat transfer and thus the heat is removed from the transformer and protected from failure. Fig.
11 shows the variable in the average temperature of the transformer with the time of the different coolants (pure transformer oil, transformed oils PCM suspension and Sic nanofluid - oil suspension and hybrid suspension). From this figure, it can be seen that there is a clear decreased in the temperature of the transformer when using paraffin wax oil and nanofluids. The reason for this is that paraffin wax absorbs the heat generated in the transformer and thus works to protect the transformer from damage by increasing its cooling efficiency. Added to Sic nanofluid with a higher thermal conductivity compared to which leads to an increase in the method of heat transfer by enhancing the thermal conductivity of the oil by dispersing the nanoparticles and increasing the thermal conductivity by increasing the size of the Sic nanofluid. Fig. 12 show the variable in the average temperature the hybrid mixture consists of a mixture of wax and nanoparticles of $5 \%$ for each substance that increases with an increase in the external temperature. For all cases, when the external temperature is $52 \mathrm{oC}$, we notice that the oil temperature is $880 \mathrm{C}$, and when adding $4 \%$ of wax with $5 \%$ of $\mathrm{TiO} 2$ nanofluid, the temperature of the transformer decreases to $84 \mathrm{oC}$, and when adding the same ratio of paraffin wax with $5 \%$ Of $\mathrm{Al} 2 \mathrm{O} 3$ nanofluid increases temperature decreases to $80^{\circ} \mathrm{C}$ and when adding the same percentage with paraffin wax with $5 \%$ of $\mathrm{Al} 2 \mathrm{O} 3$ nanofluid increases more to $77 \mathrm{oC}$ so that Sic nanofluid gives average lower temperature compared to other selected nanomaterials within the specified temperature range External. Fig. 13 shows a reduction in temperature over time between pure transformer oil and transformer oil - PCM suspension at $4 \%$ and nanofluid - oil suspension at $1 \%$. This figure it can be observed that when using a PCM suspension with $\mathrm{TiO} 2$ nanofluid, and at external temperatures 52 on Specifically, after two hours, we notice that the amount of decrease in the temperature of the transformer is $3.6^{\circ} \mathrm{C}$. As for $\mathrm{Al} 2 \mathrm{O} 3$ nanofluid, the amount of decrease is $5.5^{\circ} \mathrm{C}$ and for Sic nanofluid, the amount of temperature drop is $6.5^{\circ} \mathrm{C}$. From this figure, we find that the decrease will increase when using Sic nanofluid due to the improvement of the thermal conductivity of the oil and consequently an increase in the heat transfer rate. Fig. 14 shows a reduction in transformer temperature over time between pure transformer oil, paraffin wax at $4 \%$, and nanofluid - oil suspension at $3 \%$. At an external temperature of $52{ }^{\circ} \mathrm{C}$ and after two hours and under thermal generation, which is 60 watts. It can be observed that when using a PCM suspension with $\mathrm{TiO} 2$ nanofluid - oil Suspension, the amount of drop in the transformer temperatures is $5.8^{\circ} \mathrm{C}$, while for $\mathrm{Al} 2 \mathrm{O} 3$ nanofluid, the amount of drop is $6.8^{\circ} \mathrm{C}$. As for Sic nanofluid, the amount of decrease in temperature is $7.8^{\circ} \mathrm{C}$. From this figure, we find that the decrease will increase when using Sic nanofluid. Because of the improved thermal conductivity of the oil and thus the increased rate of heat transfer and thus kept the transformer from collapsing and failing at to the temperatures that transformers in hot regions and at overload encounter it. Fig. 15 shows a reduction in the transformer temperature with the time between pure transformer oil, paraffin wax at $4 \%$, and Sic nanofluids - oil suspension at $5 \%$. This decrease in temperature has differed greatly from the previous two forms because the Sic of nanofluid increased significantly. Because it is known when increasing Sic nanofluid thus leads to an increase in thermal conductivity, especially when using Sic nanofluid and in the case of high external temperatures to compared with other selected nanofluid over the selected range of outside temperature $52{ }^{\circ} \mathrm{C}$ where the amount of the decrease in temperatures reached $9.9^{\circ} \mathrm{C}$ in the peak period and thus this hybrid oil contributes to increasing the efficiency of the performance of the transformer from by reducing the temperature of the cooling oil and thus extending the life of all the transformed parts and increasing 
transformers efficiencies and preservation from collapse and explosion, which leads to environmental conservation. Fig. 16 shows the variation of temperatures with the weight proportions of the solid nanoparticles with adding $4 \%$ wax material for all cases where when adding $1 \%$ of titanium oxide with wax, the temperature is $54 \mathrm{oC}$ and the same percentage when adding aluminum oxide, the temperature is $50 \mathrm{oC}$ and the same percentage for silicon carbide, $49 \mathrm{oC}$. When adding $3 \%$ of titanium oxide, the temperature is $530 \mathrm{C}$ and the same percentage. When adding aluminum oxide, the temperature is $480 \mathrm{C}$, and the same percentage when adding silicon carbide, the temperature is $460 \mathrm{C}$. When adding $5 \%$ of titanium oxide, the temperature is $510 \mathrm{C}$. Moreover, when adding the same percentage to aluminum oxide, the temperature is $45 \mathrm{oC}$, and when adding the same percentage to silicon carbide, the temperature is $42^{\circ} \mathrm{C}$. We conclude from this that there is a significant decrease in temperature, especially when using silicon carbide due to the high thermal conductivity that this substance possesses compared to other materials (titanium oxide and silicon oxide) so this method can be used to protect the transformer from damage by increasing the efficiency of cooling. The figure also shows that the temperature decreases by increasing the proportion of added nanoparticles due to the further improvement of the heat transfer due to the increase in the thermal conductivity.

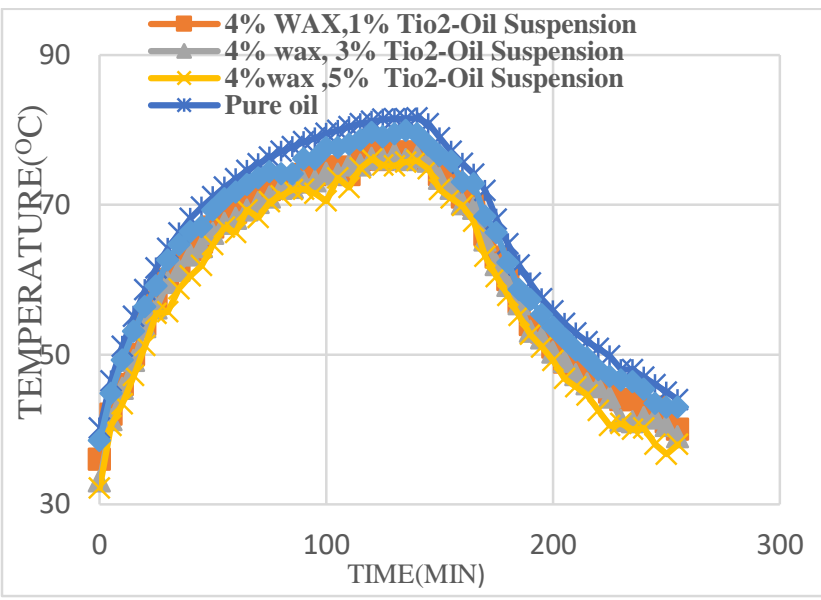

Figure 9. The variation of fluid temperature with time when using pure oil, as well as adding $4 \%$ of the wax and the mixture consisting of $4 \%$ of the wax and $\mathrm{TiO} 2$ with different ratio

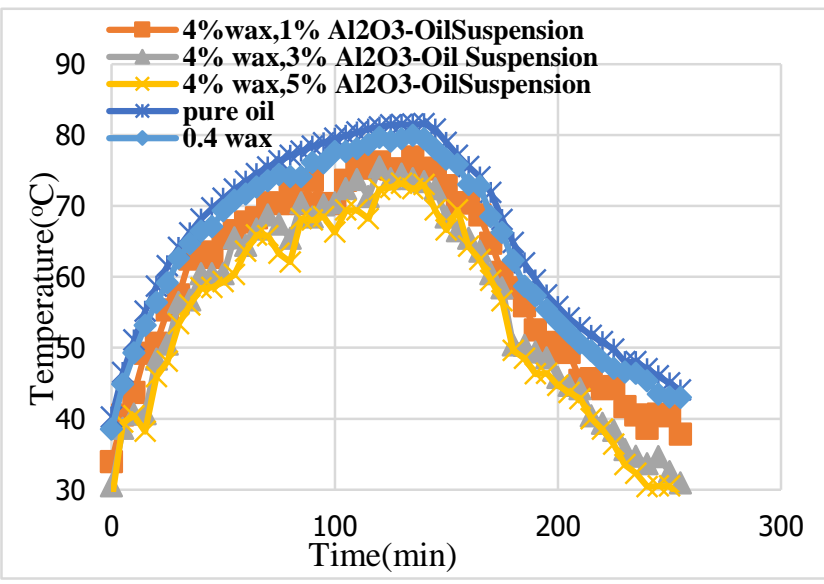

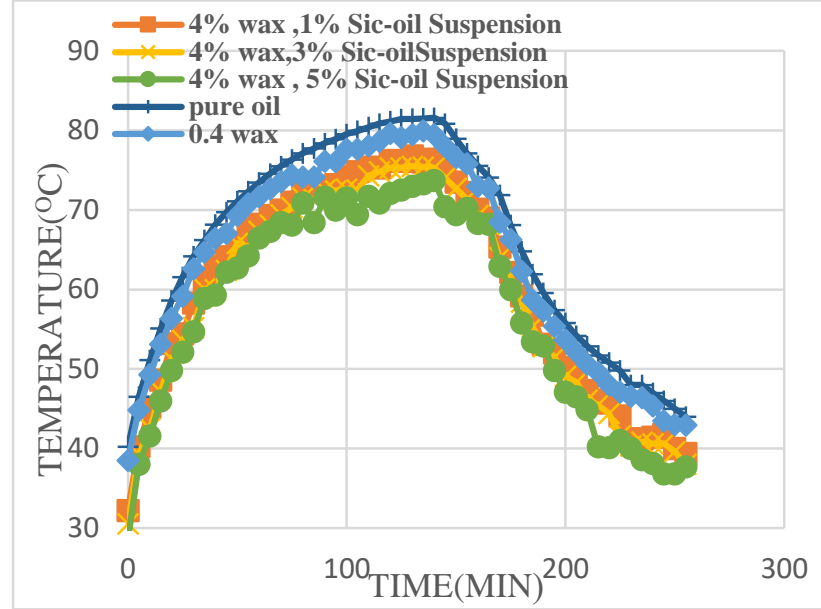

Figure 10. Temperature variation in the transformer with time when using pure oil, as well as adding $4 \%$ of wax and the mixture consisting of $4 \%$ of wax and $\mathrm{Al} 2 \mathrm{O3}$ with different ratio

Figure 11. The variation of temperatures inside the transformer with time when using pure oil, as well as adding $4 \%$ of the wax and the

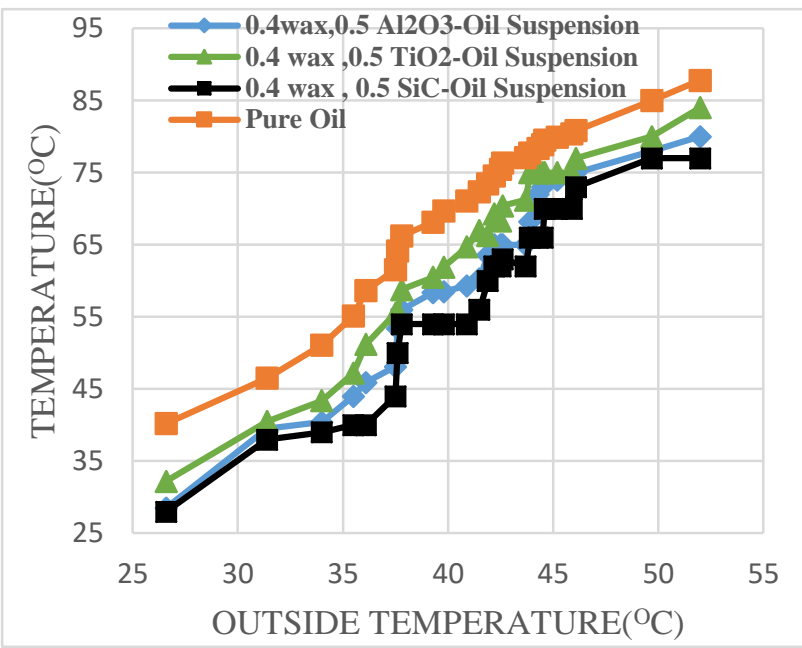

mixture consisting of $4 \%$ of PCM suspension and SiC-Oil nanofluid suspension in different ratio

a. (from 26 to $\left.52{ }^{\circ} \mathrm{C}\right)$

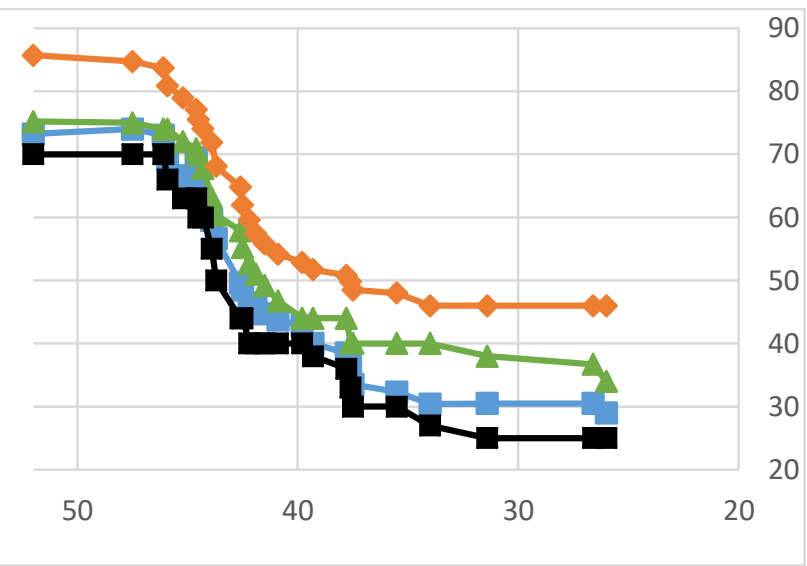




\section{b. (from 52 to 26 OC)}

Figure 12. Variation of the average fluid temperature with outside temperature presence of paraffin wax and the four transformed types with the external temperature with nanofluids

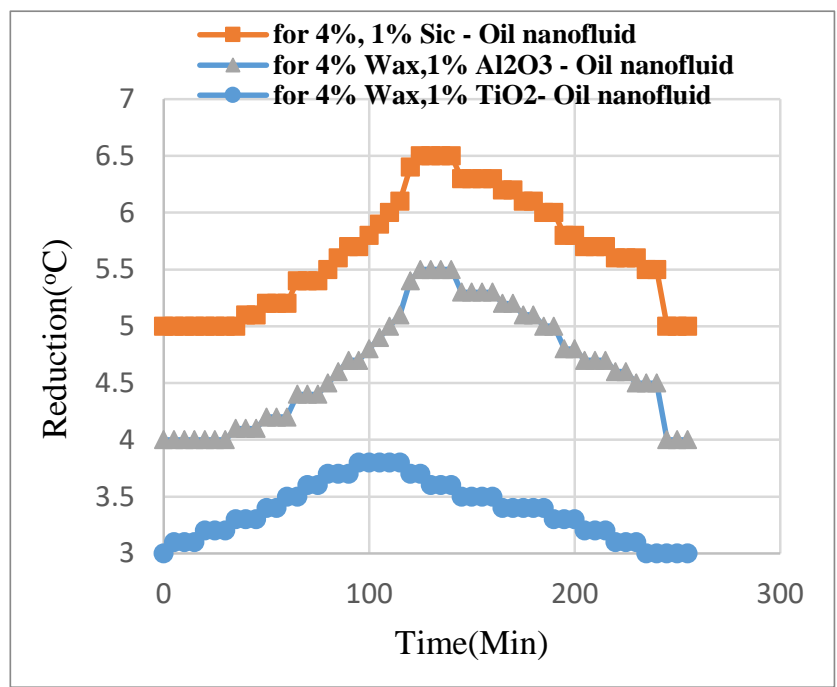

Figure 13. The reduction with time between the fluid temperature formed by each type of nanoparticle at $1 \%$ which contains $4 \%$ of PCM and the temperature of pure

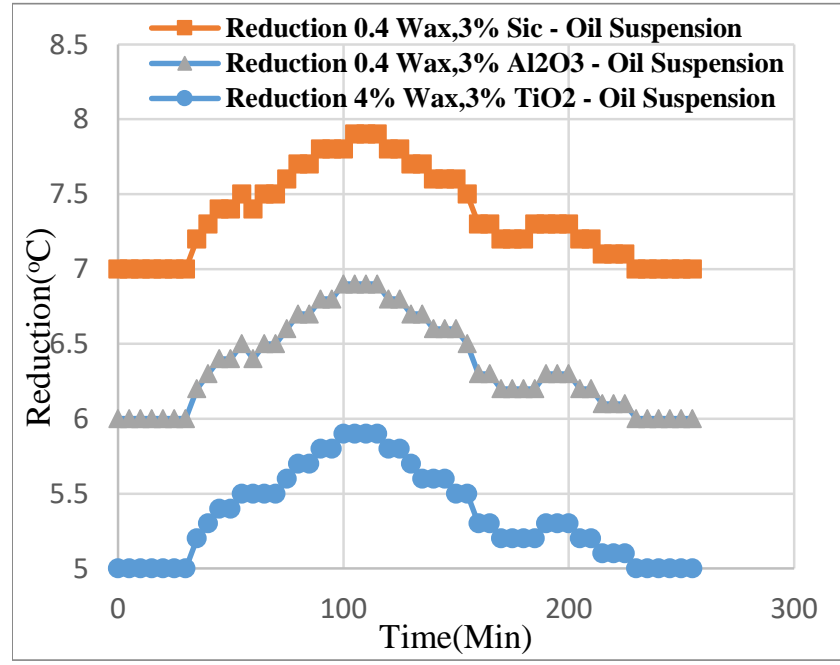

Figure 14. The reduction with time between the fluid temperature formed by each type of nanoparticle at $3 \%$ which contains $4 \%$ of $\mathrm{PCM}$ and the temperature of pure

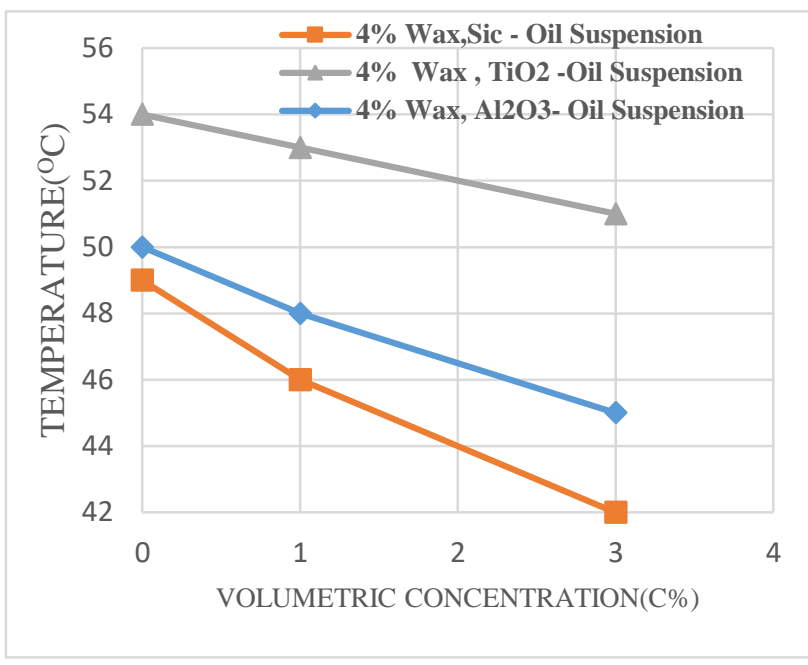

Figure 15. The reduction with time between the fluid temperature formed by each type of nanoparticle at $5 \%$ which contains $4 \%$ of PCM and the temperature

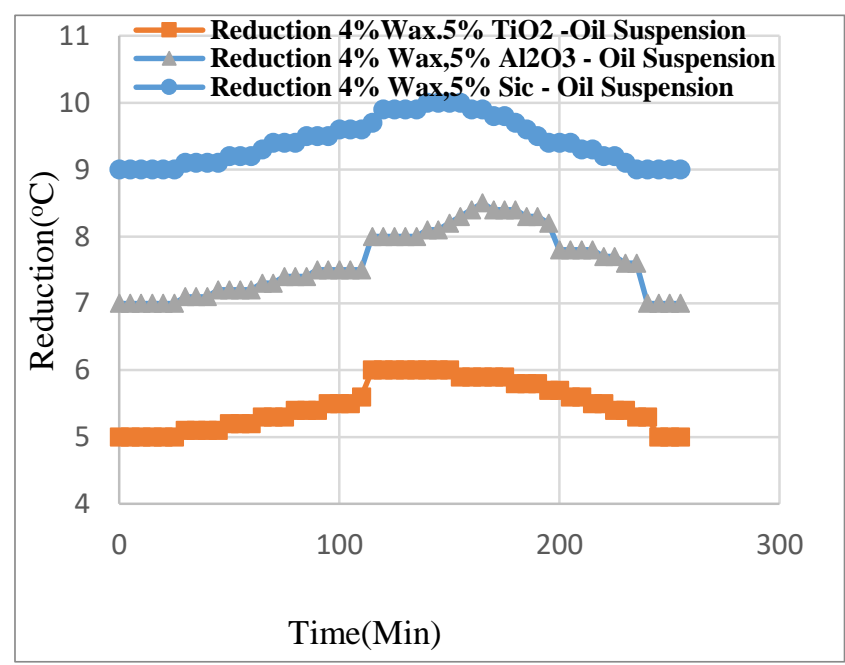

Figure 16. The variation of fluid temperature with the volumetric ratio of the nanafluids and paraffin wax 


\section{Conclusions}

In this paper, paraffin wax with nanoparticles and mixed with oil. This hybrid suspension has been experimentally studied. Different types of nanoparticles $\left(\mathrm{TiO}_{2}, \mathrm{Sic}, \mathrm{Al}_{2} \mathrm{O}_{3}\right)$ are chosen at different ambient temperatures with different mixing concentration and masses. From the results obtained, the following concluding comments may be adopted:

1- Using the oil with wax and nanoparticles leads to improved cooling of the electrical transformer parts. When the external temperature is $52^{\circ} \mathrm{C}$, the pure oil temperature is $87^{\circ} \mathrm{C}$. When adding paraffin wax with $\mathrm{TiO}_{2}-\mathrm{Oil}$, we notice a decrease in temperatures to reach $84^{\circ} \mathrm{C}$ for Pure oil. As for adding wax with $\mathrm{Al}_{2} \mathrm{O}_{3}$-Oil, there is a decrease in temperatures of up to 80 ${ }^{0} \mathrm{C}$. As for adding paraffin wax with Sic-Oil, we notice a significant decrease in temperatures of up to $10{ }^{\circ} \mathrm{C}$ to reach $77^{\circ} \mathrm{C}$ because silicon carbide possesses high thermal conductivity compared to other fluids used in this experiment.

2- temperature of the transformer that may exceed the acceptable limits. The transformer has been subjected to the conditions of collapse and the new mixed oil is very useful for hot areas and peak times and a network with large loads and high consumption as the cooling efficiency increases with increasing air temperature.

3- Wax works to protect the transformers against collapse at high air temperature during peak periods. Since it merges, the temperature varies from 50 to $57^{\circ} \mathrm{C}$.

4- The reduction temperature of the transformer depends on the mass fraction of the volume at which all the nanoparticles and paraffin wax mix with the oil. The reduction in temperature increases with the increase in the volume of the paraffin wax volume and the nanofluids. In addition, among all the studied particles, the SiC-oil gives a lower temperature for transformers followed by nanofluids with $\mathrm{Al}_{2} \mathrm{O}_{3}$ oil, etc.

5- The main purpose of this experiment is to find a new oil that contributes to increasing the cooling efficiency of transformer performance by reducing its temperature of the cooling oil, prolonging the service life of all parts of the transformer, increasing transformer efficiencies, and preserving them from collapse and explosion, which leads to maintaining an environment that save cost through Maintaining transformers and protecting them from the explosion of a huge number of transformers which work in distribution networks.

\section{REFERENCES}

[1] Nordman H., Rafsback N., and Susa D., "Temperature responses to step changes in the load current of power transformers", IEEE Transactions on Power Deliver Vol. 18, No. 4, pp.1110 - 1117, 2003.

[2] Bedell F., "History of A-C Wave Form, Its Determination and Standardization". Transactions of the American Institute of Electrical Engineers.Vol. 61, No.12, pp.864, 1942.

[3] D.J. Smith, S.G. McMeekin, B.G. Stewart and P.A. Wallace, Modeling the effectsof temperature and moisture ingress on capacitance and dissipation factor measurements within oil impregnated paper transformer bushings, Proceedings of the COMSOL Conference, Paris, 2010.

[4] Amit M., Sharma R., Sushil Chauhan and S. D. Agnihotri., "Study the Insulation System of Power Transformer Bushing" , International Journal of Computer and Electrical Engineering, Vol. 3, No. 4, pp. 544-547, 2011.

[5] Mushtaq I. Hasan., "Using the transformer oil-based nanofluid for cooling of power distribution transformer." International Journal of Energy and Environment. Vol. 8, No.3, pp. 229-238, 2017.

[6] Mushtaq I. Hasan,. "Improving the cooling performance of electrical distribution transformer using transformer oil-Based MEPCM suspension." Engineering Science and Technology, an International Journal, Vol.20, No.2, PP. 502-510, 2017.

[7] Xiang Z., Zhongdong W., and Qiang L., "Prediction of Pressure Drop and Flow Distribution in Disc-Type Transformer Windings in an OD Cooling Mode" , IEEE Transactions On Power Delivery, Vol. 32, No. 4, PP. 1655- 1664, 2017. [8] Mushtaq I. Hasan and Hind L. Tbena., "Using of phase change materials to enhance the thermal performance of micro channel heat sink", Engineering Science and Technology, an International Journal, No. 21, pp. 517-526, 2018.

[9] Mushtaq I. Hasan and Hind L. Tbena., "Enhancing the cooling performance of micro pin fin heat sink by using the phase change materials with different configurations." Advance of Sustainable Engineering and it's Application (ICASEA), 2018 International Conference on IEEE, pp. 205-209, 2018.

[10] Mushtaq Ismael Hasan, Alaa Abdlullah Abduladheem" Modifying the thermal performance of electrical distribution transformers using phase change materials (paraffin wax) " Heat Transfer-Asian Res. 2019;48:2440-2455.

[11] Oró E, deGracia A, Castell A, Farid MM, Cabeza LF. Review on phase change materials (PCMs) for coldthermal energy storage applications. Apple Energy. 2012;99:513-533.

[12] Mostafa K. M., Reza M. A., Ali I., "CFD investigation of nanofl uid effects (cooling performance and pressure drop) in mini-channel heat sink", International Communica tions in Heat and Mass Transfer, 40, pp. 58-66, 2013. [13] Eiyad A.N., "Application of nanofluids for heat transfer enhancement of separated flows encountered in a backward facing step", Int. J. Heat and Fluid Flow 29, pp. 242-249, 2008. 